REDES- Revista hispana para el análisis de redes sociales

Vol.8,\#6, Agosto 2006

http://revista-redes.rediris.es

\title{
La red de Matrix ¿En los límites de lo posible? ${ }^{1}$
}

\author{
Mariángela Petrizzo Páez \\ Fundación para el Desarrollo de la Ciencia y la Tecnología (Mérida, Venezuela) \\ I sidro Maya Jariego \\ Universidad de Sevilla (España)
}

\begin{abstract}
The Matrix trilogy offers a powerful metaphor about the man-machine convergence. This duality is efficiently represented by the the internet search engines (as Matrix centinels) and the social software applications. Both of them use widely the network representation of data.

Departing from the Social Network Analysis as a theoretical and methodological framework this paper explores the ways in which the (a) standardization of visual methods of representation, (b) community mapping, (c) global personal networks, (d) strategies for network navigation and (e) network change monitorization could be improved.
\end{abstract}

\section{Resumen}

La trilogía de Matrix ofrece una poderosa metáfora sobre la convergencia hombremáquina. Los resquicios de esa interface llevan implícita una dualidad que permite presentar el viejo tópico de la confusión entre fantasía y realidad en términos de "espejismos virtuales", como es propio de la era de la Inteligencia Artificial. Pero la navegación en estructuras paralelas a la realidad, así como la íntima conexión entre el hombre y los computadores, tienen referencias reales. Los buscadores de Internet rastrean la información sobre una trama de hipertexto, al modo de los Centinelas de Matrix. Las aplicaciones informáticas de networking permiten reproducir y ampliar las redes personales a través de la comunicación mediada por ordenador. En este artículo evaluamos (a) algunos de los buscadores de Internet y (b) de las herramientas de contactos más difundidos en la actualidad. Para ello utilizamos como referencia teórica y metodológica el análisis de redes sociales (ARS).

Tanto los buscadores como los sitios Web de contactos hacen un uso predominantemente metafórico de la idea de red, con algunas aplicaciones de la representación visual. Sin embargo, algunos desarrollos como Touchgraph (entre los buscadores) y Visible Path (para el networking de ventas) ilustran los beneficios que pueden derivarse de la aplicación sistemática del ARS en este ámbito. Como conclusión, sugerimos algunas líneas de investigación del análisis de redes que pueden resultar beneficiosas en este campo: (a) la sistematización de los procedimientos de representación visual de las redes, con fines descriptivos; (b) la identificación de comunidades; (c) la construcción de redes globales a partir de redes personales; (d) el estudio de las estrategias con las que los actores individuales hacen uso de las redes complejas, y (e) la monitorización del crecimiento de la red.

Con este bagaje, las técnicas del ARS pueden contribuir a mejorar la adecuación del diseño tecnológico a los usos sociales.

\footnotetext{
${ }^{1}$ Este artículo fue originalmente preparado para un monográfico sobre el impacto cultural de la trilogía "The Matrix". Se utilizó como material de referencia para la discusión en el grupo de trabajo: El análisis de redes sociales (ARS) y comunidades en línea: listas de distribución, plataformas de networking y peer-to-peer networks. II Congreso Internacional ONLINE del Observatorio para la Cibersociedad, 2 a 14 de noviembre de 2004. Las referencias a buscadores y plataformas de networking datan de abril de 2004, cuando fue preparado el artículo. Su fin no es otro que sugerir posibles líneas de investigación en la confluencia del ARS y las comunidades virtuales. Comunicación con los autores: Mariángela Petrizzo: petrizzo@ula.ve; Isidro Maya Jariego: isidromj@us.es.
} 


\section{O. La Conexión}

Con la aparición de la trilogía de Matrix, ha resucitado el interés desde espacios oficiales y alternativos por el desarrollo del mito de la caverna, según el cual el grueso de la sociedad estaría recluido en un sitio oscuro y sombrío, al que le habría llevado el control ejercido sobre ellos y sobre la realidad por parte de un pequeño grupo de individuos. A los primeros les hacen vivir en una especie de falsa realidad, sin tener conciencia, por tanto, de su esclavitud. Platón instaba al hombre a que intentara salir de la caverna, alcanzar la sabiduría y conocer la verdad.

Internet puede llegar a ser un mundo bastante oscuro y confuso. Las noticias, por ejemplo, constituyen un marasmo de información cuya lectura superficial puede conducir a obtener una visión parcial de la realidad. De este modo, los buscadores surgen como "ventanas" desde la caverna hacia la realidad, y posibilitan al individuo la observación de realidades paralelas de forma privilegiada.

Matrix es un mundo paralelo al real, controlado por super-ordenadores que lo construyen y sustentan, sirviéndose -entre otros instrumentos- de máquinas más pequeñas para detectar cualquier fuga del sistema y solventarla: son los llamados centinelas. Éstos recorren todo el sistema de Matrix intentando localizar los focos de resistencia. Se trata de una estructura de seguridad sustentada en la capacidad de estos pequeños robots para detectar la presencia de humanos y de otras máquinas.

La exploración de los centinelas es análoga a la forma en la que algunos motores de búsqueda recorren Internet en busca de la información puntual solicitada por los usuarios. De esta forma, según el buscador utilizado y las opciones configuradas por los usuarios, los centinelas (o algoritmos de búsqueda) recorren con mayor o menor profundidad los índices sobre distintas categorías, palabras clave y temas repartidos por Internet.

Por otro lado, la utilización de herramientas informáticas de networking, bien para realizar contactos personales o de trabajo, o para estructurar la red de contactos individuales, recuerdan la construcción de Matrix como un mundo en el que sus visitantes viven una realidad paralela a la propia gracias a la utilización de determinadas aplicaciones.

Este documento pretende explorar la utilización de la analogía de la red en los desarrollos más recientes del software social y de los buscadores de información en Internet. Sin pretender ser exhaustivos, se ha realizado una revisión del software 
más utilizado para el desarrollo de redes personales, así como de los buscadores de uso más difundido. Finalmente, se pretende vincular estas herramientas con la metáfora de la red subyacente en The Matrix.

\section{Redes ocultas}

Internet cuenta con espacios remotos y ocultos, de modo que algunos de sus contenidos son inalcanzables a través de la navegación de enlace en enlace. Según algunas estimaciones, tomando como punto de inicio una página cualquiera, podríamos llegar a través de sucesivos hipervínculos a algo menos del $25 \%$ de los documentos disponibles en Internet. Eso ocurre porque la Web tiene la estructura propia de un grafo dirigido, dividiéndose en diversos componentes. Cuenta con (a) un núcleo central altamente interconectado. Además, (b) hay un área a la que puede accederse desde el núcleo central, pero no al contrario; (c) y otra que puede conducirnos al núcleo, pero que no puede ser alcanzada desde el mismo. Finalmente, existen (d) elementos aislados del resto, y (e) pequeños canales de comunicación.

La estructura reticular se utiliza tanto para representar los enlaces de hipertexto como la base material de Internet. Por eso es tan frecuente la utilización (con diversos significados) del término "red de redes". No existe un único ordenador al que acudir en la búsqueda de información. La estructura permite organizar un conjunto prácticamente interminable de ordenadores que funcionan como hosts ${ }^{2}$ y que pueden tener direcciones ISP únicas. Siguiendo esta lógica, sobre la representación gráfica de la estructura de Internet se han realizado varios trabajos:

- An atlas of cyberspaces, cuyas imágenes reflejan el estudio de los Proveedores de Servicios de Internet (ISPs) y de los Internet backbone operators ${ }^{3}$.

- The Internet Mapping Project, que estudia la estructura de la red desde 1998, pretendiendo la obtención de información topográfica acumulable a lo largo del tiempo ${ }^{4}$.

\footnotetext{
${ }^{2}$ Cada uno de los ordenadores que funcionan como servidor de comunicaciones o información, y que está conectado directamente a Internet.

${ }^{3}$ Una especie de "red súper rápida" que conecta un área metropolitana grande con otra, y es provista por los ISPs. También se conoce con el nombre de "espina dorsal de la red" porque se constituyen como los máximos proveedores de conexión a Internet. Los resultados pueden observarse en: http://www.geog.ucl.ac.uk/casa/martin/atlas/more_isp_maps.html.

4 Algunas llamativas imágenes sobre los resultados pueden observarse en el siguiente enlace:
} 
- Finalmente, Andrei Broder y otros, presentaron el análisis de la World Wide Web utilizando la teoría de grafos $^{5}$, con los resultados que hemos resumido más arriba.

Esa estructura tan fragmentada hace difícil formarse una representación del conjunto desde una posición local. Por eso, los buscadores de Internet se manejan con ese complejo entramado de conexiones para facilitar la tarea. Veamos qué papel tiene el análisis de redes sociales en el trabajo de los centinelas de la información.

\section{La Red como metáfora visual en búsquedas electrónicas}

Desde diversos espacios, la metáfora de red llega a nuestras vivencias diarias aún de forma solapada, y en muchas más ocasiones que aquellas de las que somos conscientes. En los últimos años, hemos visto no sin asombro cómo comienza a ser creciente el interés por abordar distintas realidades, especialmente en el campo de la informática, a través del uso de la red como metáfora.

Esto es especialmente cierto para el caso de los buscadores en Internet. Hasta 1998 los buscadores más utilizados eran de una parte Altavista (http://www.altavista.com) y de la otra Lycos (http://www.lycos.com) ${ }^{6}$. Por otro lado, abundaban los buscadores pequeños y también los locales, que tenían bases de datos pequeñas y especializadas. También había más inclinación a utilizar un buscador u otro según el área geográfica desde la que se hiciera la conexión? Altavista fue uno de los primeros buscadores en incorporar el criterio de la relevancia de un sitio, basado en la cantidad de veces en la que figuraba en cada página el término o términos solicitados. Así, tendrían una mayor relevancia aquellas páginas con una mayor incidencia del término buscado y, por tanto, serían mostradas en primer lugar. Sin embargo, la llegada de Google (http://www.google.com) a la escena trasformó sensiblemente el panorama de las

http://research.lumeta.com/ches/map/gallery/

\footnotetext{
${ }^{5}$ Los resultados pueden observarse desde http://www.almaden.ibm.com/cs/k53/www9.final

${ }^{6}$ Una interesante y resumida historia de los buscadores puede observarse desde la siguiente página: http://www.monash.com/spidap3.html "Historical search engine information. Our in depth analysis of popular search engines".

7 Otros buscadores muy utilizados eran www.excite.com, y www.yahoo.com. Estos últimos representaban una innovación para las búsquedas con su clasificación temática de los links que tenía listados. El usuario tenía la opción de navegar a través de su índice temático, o hacer una búsqueda directa en el cuadro de texto. Actualmente Yahoo conserva este esquema aunque mucho más enriquecido. Otros portales como AOL (entonces como independiente y no como parte de la Times Warner), eran más visitados por el internauta estadounidense que por el suramericano, asiático o europeo, debido a que, entre otras cosas, AOL lideró durante mucho tiempo el mercado de proveedores de servicios de Internet en Estados Unidos.
} 
búsquedas masivas de información electrónica. Este proyecto surgió, si se quiere, de la casualidad. Dos estudiantes de doctorado de la Universidad de Stanford se conocen a comienzos de curso y empiezan a experimentar con el desarrollo de algoritmos de búsqueda de información. El impulso más fuerte del proyecto llegó en 1998, de la mano de Andy Bechtolsheim (cofundador de Sun Microsystems y entonces vicepresidente de Cisco Systems), amigo de un amigo en común de Larry Page y Sergey Brin. Nuevamente la metáfora de la red viene a nuestra mente.

Su sistema de búsqueda se basa en un algoritmo llamado "PageRank", utilizado en la Universidad de Stanford en un proyecto llamado "BackRub" (que luego se transformó en lo que hoy conocemos como Google). Básicamente de lo que se trataba era de elaborar un índice de las páginas (y de la información en general) en función de los links (de otras páginas en el caso de información disponible en Internet) que apuntaban a ellas. Para 1999, Google.com manejaba un promedio de 500.000 peticiones diarias y estaba posicionado entre las 100 mejores iniciativas en Internet. Hoy en día, aún cuando sigue siendo el buscador más utilizado por quienes requieren de búsquedas masivas de información, su popularidad ha descendido en favor de buscadores como Yahoo8. Sin embargo, el criterio de búsquedas que se puede hacer en Google ha sido perfilado hasta incluir búsquedas de imágenes, de contenidos en directorios o en grupos de discusión, incluso en noticias. Sus portales ya están en muchos idiomas y, además, se posibilita la búsqueda de definiciones (usando el comando define:), de palabras en determinados tipos de ficheros (usando el comando filetype: ), y además cuenta con una barra de búsqueda que se puede incorporar al navegador comercial más difundido (Internet Explorer). También cuentan con réplicas exactas en navegadores gratuitos muy difundidos como Mozilla o Netscape, y que tienen la funcionalidad añadida de posibilitar el bloqueo de ventanas emergentes (problema muy referido por los usuarios del principal navegador comercial). Más recientemente, el mercado de los buscadores ha ganado en suculencia, y se ha hecho un trofeo preciado en especial para Google y Yahoo, aunque al parecer MSN (de la compañía Microsoft) también quiere tener derecho de palabra, sobre todo después de que Google haya demostrado, con creces, que puede hacerse de la búsqueda en Internet un buen negocio sin disminuir la calidad de cara a los usuarios finales.

\footnotetext{
${ }^{8}$ Para octubre del 2003 del 40\% aproximado de usuarios estadounidenses que utilizaban motores de búsqueda, un $13 \%$ usaba Google como primera opción y un $10 \%$ Yahoo.
} 
En los primeros meses del año 2004 esta batalla por el liderato del sector de los buscadores se ha intensificado. El anuncio a comienzos de febrero pasado por parte de Yahoo de que ya no utilizaría los servicios de Google en su buscador y que estaba en capacidad de lanzar un buscador propio, marcó un punto de inflexión en la vertiginosa carrera expansiva de los buscadores. Yahoo anunciaba que frente al "PageRank" utilizado por Google, su buscador utilizaría el "WebRank" lo cual contrarrestaría la manipulación que algunos diseñadores de webs han logrado hacer en varias ocasiones a los índices de Google. Pocos días después Google anunciaba una "repotenciación" de sus índices manejando unas 4.280 millones de páginas, y dando a conocer una versión más robusta y sofisticada de su buscador. Por su parte, desde comienzos de año, MSN amenaza con el lanzamiento de su propio motor de búsqueda, aunque realmente poco se conoce al respecto9.

Pero además de intensificarse, la batalla por el control de las búsquedas y de los mecanismos de difusión de anuncios publicitarios, ha llegado a tocar también a los buscadores. Tanto Yahoo, como MSN cuentan con servicio de correo gratuito propio y de carácter limitado. El primero con una capacidad aproximada de 6MB en el buzón de correo y el segundo con apenas 2 MB de capacidad. La primera semana de abril de este año saltó la noticia sobre las intenciones de Google de ofrecer -de manera gratuita- buzones de correo de hasta 1GB de capacidad, para todo aquel que lo quisiera. La decisión de Google parece tener un "pequeño" precio que deberá ser pagado por los usuarios: Google cuenta con un motor de búsqueda que pretende rastrear en los textos de los mensajes de correo a fin de insertar mensajes publicitarios relacionados con el contenido de cada e-mail que abra el usuario. Desde Google han asegurado que, al menos dentro de las leyes norteamericanas, esta posibilidad está contemplada y no constituye delito alguno para la privacidad de los individuos, por cuanto no se trata de "revisar" su correo saliente, sino el entrante. Sin embargo, de cara al usuario esto tiene una repercusión clara: la recepción de contenidos no solicitados. Como era de esperar tanto Yahoo como Hotmail han apuntado sus armas a este flanco, pequeño pero muy importante, del proyecto de Google, compañía que asegura estar dispuesta a cambiar algunos aspectos de sus proyectos una vez sean probados por los usuarios y estos les hagan llegar sus quejas e inquietudes10. En suma el Ilamado GMail es,

\footnotetext{
${ }^{9}$ Buena información sobre el estado del arte de los buscadores puede obtenerse en inglés desde Search Engine Watch http://searchenginewatch.com/

${ }^{10}$ Uno de los escritos más clarificadores publicados en Internet sobre este tema puede leerse en Wired News: http://us.terra. wired.com/wired/tecnologia/0,1157,25944,00.html
} 
sin duda una revolución en el concepto de correo electrónico gratuitoll. No cabe duda que está llena de buenas intenciones, entre ellas la de "organizar" la información electrónica mundial, o contribuir a ello. Pero plantea un serio desafío a la seguridad virtual de los usuarios finales ${ }^{12}$.

\section{Metabuscadores}

Si la llegada de Google fue una revolución para las búsquedas masivas de información por Internet, no menos ha significado el surgimiento de los buscadores de buscadores. Desde hace unos años se viene desarrollando con éxito el concepto del metabuscador. Hace no menos de 7 años, esta idea comenzó a difundirse a través de buscadores con apariencia idéntica a los tradicionales. Quizás, uno de los que primero dieron un salto cualitativo a partir de este esquema fueron los creadores de Copernic, cuando lanzaron este producto que se servía de una interface instalable en Sistema Operativo Windows. Este buscador permite el filtrado de los resultados a través de categorías de búsquedas, de forma que incorpora los mejores buscadores de cada casa, tipos de archivos, fechas de actualización, e idioma de presentación, entre otras. La evolución de este software y de las exigencias de sus usuarios les hizo diseñar una barra de búsquedas muy similar a la de Google (o la de otros buscadores menos conocidos), pero con criterios de metabuscador, y con todas las funcionalidades de su interface para escritorio (filtrado y programación de búsquedas, selección de buscadores, búsqueda por tipos de archivos y truncamiento de cadenas entre otras).

Si bien tanto Google como Copernic (y sus similares), siguen enriqueciendo el desarrollo de aplicaciones e interfaces para las necesidades de todos los usuarios de Internet, hoy en día hay dos corrientes bastante definidas en cuanto a la difusión de los buscadores. De una parte, se encuentra el desarrollo de herramientas para ayudar a los investigadores en lo que necesiten en el desarrollo de sus tareas. Esta

\footnotetext{
${ }^{11}$ Muy en relación, además, con el espíritu de la empresa visible a través de sus servicios: barra de búsqueda (Google Toolbar), Google Calculator (que permite utilizar los ordenadores ociosos para que procesen pequeños paquetes de información), el servicio de búsquedas específicas (http://www.google.com/options/specialsearches.html), el servicio de respuestas (http://answers.google.com/), los catálogos (http://catalogs.google.com/), directorio (http://www.google.com/dirhp), el servicio de compras pequeñas (http://froogle.google.com/), grupos (http://www.google.com/grphp?hl=en\&tab=wg\&ie=UTF-8\&oe=UTF-8), la búsqueda de imágenes (http://www.google.com/imghp?hl=en\&tab=wi\&ie=UTF-8\&oe=UTF-8), la búsqueda de noticias (http://www.google.com/nwshp), el directorio universidades (http://www.google.com/options/universities.html), la búsqueda en teléfonos móviles (http://www.google.com/options/wireless.html), y algunas características configurables para cada búsqueda, como tipo de archivo, búsqueda restringida a un sitio web, búsqueda de mapas de carreteras entre otros (http://www.google.com/help/features.html). Además Google incluye una barra de búsqueda para Internet Explorer (Google Toolbar) y para el escritorio (Google Desktop).

12 Al respecto, en CNET news:

http://news.com.com/2100-1032_3-5184090.html?tag=nefd top
} 
idea se desarrolla de forma comercial en entornos como Questia y Gurunet (http://www.questia.com), y tienen mucha difusión ya que explota el concepto de búsqueda en libros, revistas y diccionarios, con posibilidades de tener acceso al documento en texto completo, a un precio realmente módico. Paralelo a ello, han surgido índices de publicaciones que, aunque no cuentan con entorno gráfico, basan su estructura en los vínculos producidos gracias a citaciones "enlazadas" de documentos científicos. Un buen ejemplo de esto es el sitio Citeseer (http://www.citeseer.com). Otra modalidad de búsqueda es la mostrada por la compañía Amazon (http://www.amazon.com), que tiene indexados buena parte de su stock de libros, y permite la búsqueda de cadenas de palabras incluso en el contenido de los libros que tiene bajo ese índice. Esta compañía muestra un valor añadido en sus búsquedas, al vincular los títulos seleccionados por un usuario con la selección de títulos relacionados que hayan recomendado o comprado otros usuarios. En este sentido, la idea de la red se desarrolla un paso más allá de la simple metáfora, en tanto que posibilita, incluso, conocer un mapa de gustos y preferencias de los usuarios que se pasean por las tiendas de Amazon ${ }^{13}$.

Por otro lado, la llegada de nuevas opciones en los buscadores tradicionales también ha contribuido a enriquecer el panorama. Buscadores como Vivisimo (http://www.vivisimo.com) trabajan con el concepto de clustering de los resultados. Según esta idea, las búsquedas son mostradas en un listado global, pero se presenta al usuario un menú gracias al cual estos resultados pueden ser explorados por categorías. Estas categorías se obtienen del análisis textual de las páginas derivadas de la consulta. El clustering engine, tal y como lo definen sus creadores, utiliza una vieja idea de la inteligencia artificial para agrupar las páginas en función de lo buena que son sus descripciones. Dicho en otras palabras, este buscador organiza y cataloga los resultados de forma automática, atendiendo a las descripciones generadas por su algoritmo y vinculadas con los contenidos de las páginas obtenidas en los resultados (y lo hace incluso con páginas en idiomas distintos del inglés). Esta organización es, a su vez, indexada, mostrando entre los primeros grupos aquellos que cuenten con una mejor definición. La idea del conceptual clustering enlaza la formación de grupos de páginas con la construcción de una definición común que facilite su posterior localización por parte del usuario.

\footnotetext{
${ }^{13}$ Es de destacar el estudio realizado por Valdis Krebbs titulado "The Social Life of Books Visualizing Communities of Interest via Purchase Patterns on the WWW" $y$ disponible desde http://www.orgnet.com/booknet.html. El autor analiza las redes que se forman de algunos servicios de Amazon, como el Ilamado "Customers who bought this book also bought these books" que permite a quien desee adquirir un libro ver qué otros títulos han comprado mayoritariamente quienes han adquirido el libro que él desea. El análisis perfila conclusiones interesantes que bien pueden ser utilizadas por los consumidores como estrategias de compras futuras en el portal Amazon.com.
} 
Otro buscador bastante potente que también lleva implícita la noción de red es Teoma (http://www.teoma.com). El algoritmo desarrollado en este caso, tiene que ver directamente con el análisis de Internet como un conjunto de comunidades generadas de forma "natural" en torno a temas específicos. De este modo, Teoma obtiene un rango de popularidad de las páginas en función de su difusión entre las comunidades de expertos de áreas específicas. Este algoritmo es llamado por sus creadores Subject-Specific Popularity, y tiene mucho que ver con los links que se dirigen a otras páginas, provenientes de páginas referidas a temas iguales o similares. Este algoritmo es un refinamiento del algoritmo utilizado por Google. En el caso de Teoma la popularidad de un sitio no se basa en la que el usuario de forma individual le otorgue, sino en los links provenientes de páginas con similares contenidos. De esta forma, Teoma es menos vulnerable a ver alterado su índice a través de, por ejemplo, correo spam destinado a elevar de forma artificial el tráfico a una página en particular, cosa que le ha sucedido a Google en alguna ocasión ${ }^{14}$.

Esto ocurre en un momento en el que nuevas herramientas de búsqueda intensiva de información se han difundido entre los usuarios de Internet, y en el que estas herramientas han comenzado a desarrollar importantes soportes gráficos. Si a comienzos del 2003 los asiduos usuarios de la búsqueda de información en Internet eran sorprendidos con un entorno muy especializado de meta búsquedas y de presentación gráfica como Kartoo (http://www.kartoo.com), a mediados del 2003 ha sucedido lo propio con Grokker2 (http://www.groxis.com) y con TouchGraph (http://www.touchgraph.com/).

En el caso de Kartoo, se trata de un metabuscador que presenta sus resultados en un mapa que, a través de esferas cuyo tamaño está relacionado con la pertinencia (puntuación) de cada una de las páginas, indica también la vinculación entre éstas. El entorno permite la configuración de los buscadores utilizados, formato específico de muestra de resultados ( $\mathrm{html}$ y flash), extensión de los mismos y establecimiento de la interface en modo simple o avanzado. Además ofrece también un filtro para padres y permite el almacenamiento, impresión y envío por e-mail de los resultados. Según el usuario se pasea con el cursor sobre cada una de las esferas, se muestra información sobre la página o sitio en formato tan reducido o amplio

\footnotetext{
${ }^{14} \mathrm{Y}$ que ha llevado a sus desarrolladores a diseñar un mecanismo llamado google dance, que pretende actualizar mensualmente el índice creado por su algoritmo (google search engine), y que consiste en la actualización de los índices presentes en cada uno de los datacenters que Google utiliza para abaratar sus costos. Estos índices no son actualizados de manera automática, sino consecutiva, hasta que todos los datacenters ya tienen el índice actualizado y ha sido reenviado a Google. Esto puede, desde la visión del usuario, durar algunos minutos, y durante este tiempo, pueden obtenerse resultados totalmente distintos en búsquedas iguales, en función de si el datacenter al que se ha redirigido la búsqueda ya cuenta o no con el índice actualizado.
} 
como el usuario lo haya decidido. Como valor añadido, el resultado se muestra con un menú por categorías, derivadas de los contenidos a los que se refieren las páginas obtenidas de la consulta.

Por su parte, aunque el metabuscador Grokker también muestra los resultados en forma gráfica, su interface los dibuja en círculos concéntricos organizados atendiendo a su prioridad. Los filtros pueden ser cambiados y se pueden configurar los buscadores utilizados. Además, Grokker también permite la búsqueda de determinadas cadenas en los documentos del disco duro. A diferencia de Kartoo que trabaja utilizando el flash, Grokker cuenta con una interface instalable en el ordenador del usuario que se sirve de la tecnología desarrollada por Microsoft para su explorador.

Finalmente TouchGraph (http://www.touchgraph.com) es, con diferencia, el navegador que trabaja de forma más directa con la noción de red. La idea que desarrolla es la de rastrear los links a los que apunta una dirección http introducida por el usuario, y desplegar los resultados de forma gráfica a través de una red. Se sirve de la tecnología Java (http://java.sun.com) y tiene varias versiones de sus búsquedas. Por un lado hace una búsqueda de sitios relacionados con el http consultado a través del buscador Google. Además, presenta herramientas similares para obtener mapas de búsquedas en Amazon (TouchGraph Amazon Browser), wikis y en los blogs construidos a través de LiveJ ournal (TouchGraph Livejournal Browser). Quizás la herramienta más referida sea el TouchGraph Google Browser, sin embargo tiene el inconveniente de no permitir la realización de mapas con base en búsquedas de términos. Esta limitación es parcialmente solucionada por una herramienta Ilamada Google Sets (http://www.langreiter.com/space/google-setvista), bastante ilustrativa, porque devuelve un mapa con clusters de la información obtenida, aunque no es muy certera en sus resultados. Para muestra un botón: no posibilita la búsqueda de palabras exactas, y muchas veces los resultados obtenidos no se adaptan a los esperados por el usuario ${ }^{15}$.

\section{Visita la tabla comparativa de buscadores}

\section{Estructura en red y efectividad en la búsqueda de información}

Internet es una herramienta compleja de difusión electrónica de información. Su

\footnotetext{
${ }^{15}$ Esto es especialmente válido en términos que son al mismo tiempo nombre de una persona y de una ciudad por ejemplo. $O$ en los casos referidos a estudios muy específicos o disciplinas muy especializadas. Sin embargo, como punto de partida es una muy buena herramienta.
} 
funcionamiento se encuentra simplificado, en extremo, de cara a su usuario final, permitiéndole localizar en cuestión de segundos documentos electrónicos (imágenes, texto, música, foros, webs, wikis, blogs, y otros) con independencia prácticamente total del sitio en el que se encuentren físicamente almacenados. Su naturaleza virtual es la característica más destacada. Cuando se visita una página web determinada, en realidad no se está utilizando para ello los recursos de navegación de la máquina en la que está alojada. Esta "visita" no equivale, por tanto, a desplazarse a una biblioteca o a un museo. A través de nuestros sistemas de conexión a Internet primero y de las múltiples herramientas de las que se dispone para pasear por Internet de forma activa (haciendo una búsqueda de información) o pasiva (navegando tras los enlaces propuestos desde una página inicial), se muestra visualmente una copia de la página que se desea consultar y que está almacenada físicamente en la dirección que se ha teclado. De este modo, y entre otras cosas, se posibilita la visita a una misma dirección de Internet y de manera simultánea a tantos usuarios como su servidor de alojamiento permita, o que descarguemos en un ordenador una copia de cualquier fichero disponible en Internet sin eliminarlo del servidor en el que se encuentra.

La información disponible en Internet no está ordenada, de ahí que su localización no sea ni fácil ni inmediata. Esta es la importancia de contar con herramientas que aseguren niveles de confiabilidad de la información obtenida. Para el año 2003 el 13 por ciento del tráfico que llegaba a los sitios Web provenía de enlaces desplegados en buscadores, con respecto al año anterior esto refleja un incremento de casi el cien por cien. Además, para el mismo año el 41 por ciento de los usuarios que visitaban un sitio de compras llegaban allí a través de una búsqueda en Internet. Sin embargo, ninguno de los buscadores ha demostrado su infalibilidad frente a modificaciones externas, aunque sí han probado ser muy eficientes en su trabajo de decantar la información en función de las necesidades de los usuarios y las empresas $^{16}$.

En tanto que los principales navegadores utilizan distintos algoritmos de búsqueda, los resultados obtenidos pueden diferir sensiblemente según el área en la que se enmarque la misma. Así, una palabra consultada que esté vinculada con un área con una importante afluencia de tiendas de comercio electrónico, por ejemplo, puede arrojar resultados bastante similares entre los diversos buscadores, sobre

\footnotetext{
16 Desde la página Search Engine Watch http://searchenginewatch.com/reports/index.php, puede tenerse acceso a diversos artículos sobre calidad, puntuación y revisiones de los buscadores.
} 
todo si en el sector se observa un oligopolio. Cosa contraria puede suceder con búsquedas muy específicas que pueden no estar reflejadas en los índices de búsqueda manejados por algunos buscadores. Las diferencias se centran no sólo en el número de resultados, que puede variar de forma significativa, sino también en el orden de éstos (relevancia) y en el contenido de la hoja de resultados. De allí que una de las primeras recomendaciones para el uso de Internet como herramienta de búsqueda intensiva de información, sea la contrastación de los resultados obtenidos con búsquedas simultáneas en dos buscadores que utilicen algoritmos distintos, o con un metabuscador que incluya entre sus fuentes, este criterio. Esto garantiza, principalmente, la pertinencia de la información obtenida.

Para noviembre del 2003, como se reseña en Search Engine Watch, en su "conScore Media Metrix Search Engine Ratings"17, las búsquedas hechas por los usuarios en estados unidos, se distribuían como sigue:

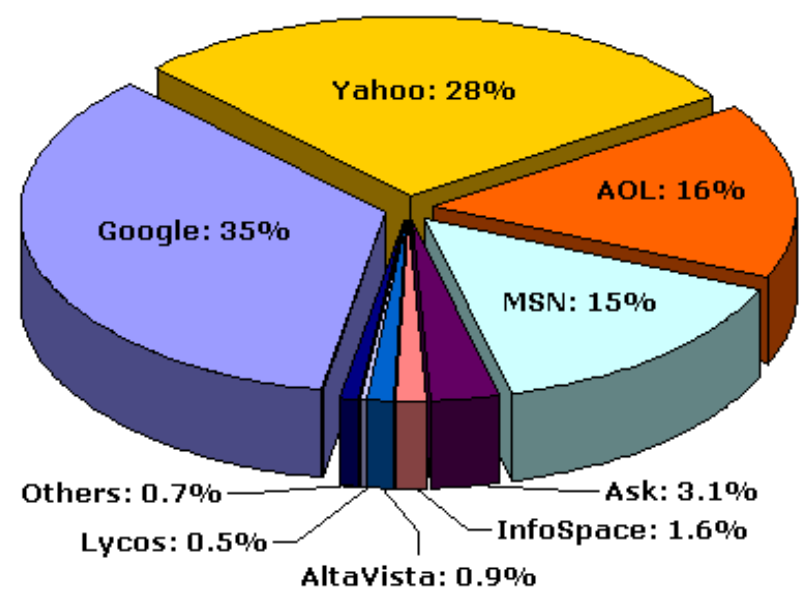

Tomado de http://searchenginewatch.com/reports/article.php/2156431. Consulta: 5 de abril del 2004.

Los resultados muestran las consultas hechas para cualquiera de los productos de los buscadores reflejados. Agrupando en Google, por ejemplo, cualquier búsqueda hecha en Google (imagen, texto, noticia), y en Yahoo cualquier búsqueda hecha en Yahoo (deportes por ejemplo). Como se ve, el espacio de preferencias de los usuarios entre Google y Yahoo es bastante similar. Probablemente Google esté apostando por diversificar sus servicios como una medida para lograr una mayor diferenciación entre los usuarios.

Pero además, y como se dijo antes, una diferencia importante la puede marcar el algoritmo utilizado. Para ilustrar la repercusión de los distintos algoritmos en los

${ }^{17}$ El artículo completo está en: http://searchenginewatch.com/reports/article.php/2156431 
resultados obtenidos de una búsqueda, se muestran a continuación el reporte de datos y documentos obtenidos en los diferentes buscadores y meta-buscadores descritos, utilizando como criterio de búsqueda el término "social network" (red social).

\begin{tabular}{|l|l|}
\multicolumn{1}{|c|}{ Buscador } & \multicolumn{1}{|c|}{ Resultados } \\
\hline Google & $\begin{array}{l}267.000 \text { páginas sólo en la búsqueda de páginas. No se ha utilizado ni el comando } \\
\text { define, ni filetype ni related, entre otros, por no estar disponibles en otros } \\
\text { buscadores. }\end{array}$ \\
\hline Questia & 2239 libros, 2162 artículos en journals, 111 artículos en revistas y 5 en periódicos \\
\hline CiteSeer & $\begin{array}{l}125 \text { documentos en una búsqueda hecha sobre referencias en documentos } \\
\text { científicos. }\end{array}$ \\
\hline Vivisimo.com & 162 páginas agrupadas en 11 categorías principales. \\
\hline Teoma.com & $\begin{array}{l}75.600 \text { páginas agrupadas en } 6 \text { categorías de referencias en función de su subject- } \\
\text { clustering popularity. }\end{array}$ \\
\hline Kartoo.com & $\begin{array}{l}225.000 \text { páginas localizadas, categorizadas en 22 grupos o clusters. Es importante } \\
\text { apuntar que Kartoo no tiene entre sus buscadores a Google ni Vivisimo. }\end{array}$ \\
\hline Grokker2 & $\begin{array}{l}809 \text { páginas agrupadas en 258 categorías. Entre sus buscadores consultados no se } \\
\text { encuentra ni Google ni Vivisimo. } \\
\text { El resultado de las búsquedas es una representación gráfica en formato de red. } \\
\text { Visita un ejemplo de la pantalla de resultados. }\end{array}$ \\
\hline Touchgraph &
\end{tabular}

Tabla 1. Resultados obtenidos en los diferentes buscadores con el término "social network"

Esta marcada inconsistencia de los resultados obtenidos entre los distintos buscadores, viene siendo estudiada, desde hace algún tiempo, por Greg Notess (http://www.notess.com/), tanto de forma individual como de forma comparativa entre los diferentes buscadores. En general, las inconsistencias encontradas tienen que ver con problemas de forma del algoritmo utilizado. Así, se apunta a problemas como el tiempo de espera para la obtención de respuesta, el truncamiento de palabras o frases, la distinción entre mayúsculas y minúsculas, y un límite preestablecido de los resultados a mostrar. Una explicación completa de las inconsistencias encontradas está disponible en:

http://www. searchengineshowdown.com/inconsistent. shtml

En cualquier caso, tras la revisión realizada, queda claro que en lo referente a los buscadores de Internet se impone un criterio pragmático: su calidad depende del grado de pertinencia de los resultados de la búsqueda de información. Dicho de otra forma, el algoritmo es bueno si responde a las necesidades del usuario.

En ese sentido, hay (al menos) dos tipos de contribuciones que las técnicas de análisis de redes sociales podrían hacer en este ámbito, refiriéndose respectivamente a (a) la presentación de los resultados y (b) el sistema de búsqueda propiamente dicho: 
- En primer lugar, la representación espacial de los sociogramas parece ajustarse especialmente bien a la naturaleza de la cognición humana. Facilitan una comprensión intuitiva de la información descriptiva, y quizá por eso están siendo utilizados por algunos buscadores para informar de los resultados obtenidos. Por eso un campo interesante de investigación sería la sistematización de las rutinas que se siguen en el examen exploratorio de los datos relacionales. Pese a que, con frecuencia, se ha desdeñado por sus limitaciones analíticas, constituye una herramienta descriptiva enormemente útil.

- En segundo lugar, la estructura (física y de hipertexto) de Internet resulta especialmente apropiada para el análisis reticular. De hecho, la disponibilidad de grandes bases de datos relacionales en Internet ha permitido desarrollos teóricos significativos en el análisis de redes complejas. Como hemos comprobado, el análisis de las propiedades de Internet, derivadas de su carácter de grafo dirigido; junto al diseño de Touchgraph ilustran las oportunidades de este tipo de análisis. Probablemente, el tipo de análisis que más se ha desarrollado en este terreno consiste en la identificación de comunidades. Por ejemplo, reconociendo conglomerados de páginas Web que tienen más enlaces entre sí que con su entorno.

Parece entonces que los buscadores abren una ventana "al otro lado", y que se encuentran en un proceso de mejora técnica progresiva. Pero, dicho esto, es necesario cerrar este apartado con una nota de cautela. La actualización de todo el potencial de los buscadores depende del usuario final. Queremos decir que hay grandes diferencias individuales en el uso que se hace de dichos recursos. Ni todos los usuarios recurren a buscadores para su navegación en Internet, ni todos son igualmente efectivos en la aplicación de estrategias de búsqueda.

\section{Redes Prestadas}

En diciembre de 2003 empezó a funcionar Econozco. Se trata de la primera aplicación informática de networking profesional en castellano. Por su concepción y su diseño tecnológico es una plataforma enormemente prometedora. Como ocurre en este tipo de servicios, el crecimiento de la red de subscriptores se produce -en gran medida- por invitaciones en cadena. Por ejemplo, la primera autora de este artículo invitó al segundo, que a su vez invitó a un contacto personal: Mariángela (MAPP) invita a Isidro (IMJ) que invita a María (MNL). Secuencias de este tipo junto a los enlaces que van surgiendo entre los que ya son miembros- acaban conformando (en sus primeros meses de funcionamiento) un tipo de red como la 
que vemos representada a continuación.

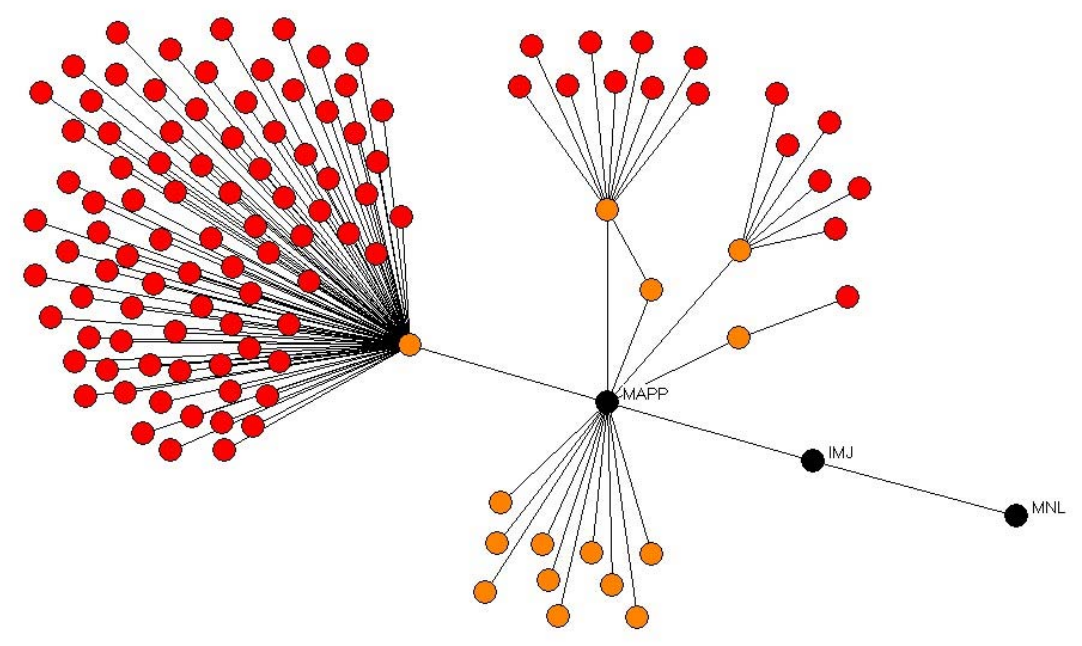

El sociograma representa el conjunto de contactos a dos grados de distancia de los tres nodos de la cadena en cuestión, destacados en negro. Además se distinguen en naranja y rojo los individuos que están - respectivamente- a uno y dos pasos. Como podemos comprobar, Mariángela abre las puertas a todo un entramado de contactos para Isidro y María (con la frontera de seis pasos de distancia, según las prescripciones técnicas de la plataforma). En abril de 2004, sólo 4 meses después de entrar en funcionamiento, Econozco ha alcanzado los 12.000 miembros. En esa misma fecha, a través de sus 17 contactos, Mariángela puede alcanzar un $30 \%$ del total de suscriptores. Sólo por estar vinculado con este primer nodo, I sidro llega a casi dos tercios de la red personal de Mariángela. En el tercer paso de la cadena, María dispone de la mitad de la red personal de Isidro y un tercio de la de Mariángela. Los resultados están resumidos en la siguiente tabla.

\begin{tabular}{|c|c|c|c|}
\hline Grados de distancia & Mariángela (MAPP) & I sidro ( I MJ ) & María ( MNL) \\
\hline Contactos directos & $17 \operatorname{contactos}(0.5 \%)$ & $2 \operatorname{contactos}(0.1 \%)$ & 1 contactos $(0.1 \%)$ \\
\hline A 2 grados & $103 \operatorname{contactos}(2.9 \%)$ & $17 \operatorname{contactos}(0.7 \%)$ & 1 contactos $(0.1 \%)$ \\
\hline A 3 grados & $288 \operatorname{contactos}(8.0 \%)$ & $103 \operatorname{contactos}(4.4 \%)$ & $17 \operatorname{contactos}(1.4 \%)$ \\
\hline A 4 grados & $761 \operatorname{contactos}(21.2 \%)$ & $288 \operatorname{contactos}(12.4 \%)$ & $103 \operatorname{contactos}(8.8 \%)$ \\
\hline A 5 grados & $1148 \operatorname{contactos}(32.0 \%)$ & $761 \operatorname{contactos}(32.8 \%)$ & $288 \operatorname{contactos}(24.8 \%)$ \\
\hline A 6 grados & 1265 contactos $(35.3 \%)$ & $1148 \operatorname{contactos}(49.5 \%)$ & $761 \operatorname{contactos}(64.9 \%)$ \\
\hline $\begin{array}{l}\text { Total de miembros } \\
\text { en su red personal }\end{array}$ & $\mathbf{3 5 8 3}$ & $\mathbf{2 3 1 9}$ & $\mathbf{1 1 7 1}$
\end{tabular}

Tabla 2. Número de miembros en la red personal por grados de distancia Las cadenas de conocidos nos incorporan a mundos sociales amplios y productivos con sólo una conexión. Tanto es el valor de una relación personal. Pero a medida que la red va más allá de una secuencia lineal de conocidos, la telaraña se va tejiendo, se hace más compleja, y con ello se multiplican nuestras oportunidades. 
Veamos cuáles son las herramientas que ayudan a construir esta estructura "paralela" de relaciones interpersonales.

\section{El software social y la capitalización de las redes personales}

A finales de 2003 la influyente revista sobre la Nueva Economía Business 2.0 (http://www.business2.com) reconoció como “Tecnología del Año" el campo emergente de las aplicaciones de redes sociales. Desde que en 1997 entrara en funcionamiento el sitio SixDegrees18 han aparecido decenas de programas informáticos que - por lo general, a través de sitios Web- pretenden gestionar los contactos personales para obtener un rendimiento comercial, mejorar las oportunidades profesionales o constituir comunidades virtuales basadas en la lógica del intercambio generalizado. Habitualmente hacen un uso meramente metafórico o descriptivo de la red de contactos, pero - como algunos casos ponen ya de manifiesto- constituyen un campo privilegiado para la aplicación del análisis sistemático de redes sociales. Esta visión renovada de las técnicas de networking se ha dado en llamar "software social", y se aplica a iniciativas que, en la mayoría de los casos, se encuentran aún en versión Beta. A continuación, repasamos algunas de las herramientas que más han destacado en esta primera fase de experimentación, ya sea con usos sociales o comerciales.

\section{Networking con fines comerciales y profesionales}

Es un lugar común decir que las personas obtienen recursos sociales y económicos a través de su red de contactos personales. Sin embargo, no es nada fácil gestionar ese fondo de relaciones. Incluso el individuo mejor conectado sólo es consciente de una pequeña proporción de las relaciones disponibles en su red social. Del mismo modo, la información local accesible no siempre es suficiente para navegar con éxito hasta los bienes y apoyos requeridos. Por eso el software social pretende convertirse en un asistente para la gestión de contactos.

La idea que inspira este tipo de servicios es que la confianza se convierte en un capital en las relaciones comerciales y profesionales. Tener conocidos comunes facilita el acceso a posibles clientes, y puede ser clave en la negociación de un acuerdo comercial. Para sacar partido a ese "capital relacional" se han desarrollado dos tipos de aplicaciones informáticas:

\footnotetext{
18 Este sitio pionero se inspira en la idea de los "seis pasos de distancia" de Stanley Milgram (véase, Maya Jariego, 2003) e incorpora los contactos personales y profesionales en una comunidad en línea, con la idea de facilitar la búsqueda de empleo o el establecimiento de contactos. En la actualidad la página Web está inactiva (http://www.sixdegrees.com), pero anuncia su próximo relanzamiento. Otro sitio que se encuentra entre los pioneros es True Peers (http://www.truepeers.com).
} 
- Por un lado, se están diseñando programas para el análisis sistemático de las redes de contactos. Esto proporciona al usuario una visión global de su red, y mejora los procesos de intermediación de carácter comercial. Es el caso de los programas Visible Path y Spoke.

- Por otro lado, se están poniendo en marcha dispositivos que ofrecen un lugar de encuentro, en los que los usuarios vuelcan la información de sus redes personales con el fin último de promover nuevas relaciones. Ejemplos de este tipo de programas en el ámbito comercial son Linkedin y Ryze.

Visible Path (http://www.visiblepath.com) está diseñado para ayudar a la fuerza de ventas en la empresa, con el objetivo de aumentar el volumen de negocios y reducir el ciclo de comercialización. Se trata de una plataforma que se integra en el departamento de ventas de cualquier organización y permite almacenar y analizar datos relacionales. Los datos se obtienen generalmente a partir del correo electrónico, las agendas personales, los encuentros programados por los vendedores o el software propio del departamento comercial. Con esa información es posible elaborar desde mapas de las redes personales hasta el entramado de contactos de toda la organización. También es posible compartir los datos con otras empresas -más allá de la propia Intranet-, extendiendo la cobertura en la búsqueda de contactos. A través de la aplicación de más de 30 algoritmos patentados - desarrollados con la colaboración del profesor Stanley Wasserman ${ }^{19}$, de la Universidad de Illinois- Visible Path analiza la estructura de las relaciones, y permite identificar caminos de grado $\mathrm{n}$ entre un proveedor y un cliente potencial ${ }^{20}$.

El resultado final es que la sistematización de datos tales como la frecuencia de comunicación interpersonal por correo electrónico, o la demora en la respuesta, sirve para reducir el número de intermediarios en el proceso de compra-venta, o bien para determinar qué individuo en tu red personal de contactos se encuentra más "cerca" de un objetivo comercial. Concretamente, según datos de la empresa ubicada en Nueva York, Visible Path reduce en un $27 \%$ el ciclo de compra-venta y aumenta en un $10 \%$ los acuerdos comerciales.

Un software de características muy similares es Spoke (http://www.spoke.com). En

\footnotetext{
19 Wasserman es co-autor de uno de los manuales de referencia del Análisis de Redes Sociales (Wasserman, S. \& Faust, K., 1994, Social Network Analysis, New York: Cambridge University Press), y, como parte del Comité de Dirección, es el responsable científico del diseño de Visible Path.

20 Un camino (path) es la "secuencia de nodos y relaciones en la cual cada nodo sólo puede ser usado una vez" (Glosario de Análisis de Redes Sociales, elaborado por la Lista Redes en el congreso del International Network of Social Network Analysis de Budapest, en abril de 2001, cfr. http://revistaredes.rediris.es/glosario.pdf). La virtualidad de Visual Path está en la identificación de geodésicos, es decir, de los caminos más cortos entre dos nodos.
} 
este caso se trata de una aplicación cliente que se integra con el programa de correo electrónico, de modo que el usuario individual obtiene información sistematizada sobre su red personal. Al integrar toda esta información se puede construir un mapa de la red de contactos de la compañía, y también existe la posibilidad de compartir información para acceder a relaciones fuera de la empresa. Aunque se basa en fundamentos del análisis de redes, -no en vano el propio Mark Granovetter $^{21}$ es consultor científico de esta Start Up del Silicon Valley-, parecen predominar los usos descriptivos y de representación visual (en comparación con la perspectiva más analítica de Visible Path). Por ejemplo, se obtiene un informe sobre la fortaleza de la relación con los nodos de nuestro interés, pero la gestión de contactos se basa en gran medida en una aproximación de "quién conoce a quién". La experimentación con el programa está suponiendo entre un 20 y un 30\% de incremento en los contactos comerciales, según los datos aportados por Spoke.

Entre los sitios para la socialización profesional destaca una iniciativa que ha conseguido conformar su clientela con miembros de la elite de los negocios en Estados Unidos. Linkedin (http://www.linkedin.com) es un sitio Web orientado a facilitar el establecimiento de contactos entre managers y ejecutivos. En su primer año de funcionamiento se está revelando como un medio excelente para el reclutamiento de personal, la obtención de consejo experto y la búsqueda de socios. En consonancia con una clientela compuesta en su mayor parte por directivos de alto nivel, la interface es enormemente funcional, y prescinde de los detalles más costosos en tiempo en los procedimientos de alta, solicitudes y mantenimiento. La subscripción se lleva a cabo proporcionando un mínimo de datos personales y profesionales, y hay controles que evitan que los participantes se vean saturados por demandas de ayuda o contacto. Los usuarios disponen de información estadística sobre los miembros de su red (aquellos con los que está enlazado a través de conocidos), y la plataforma permite la búsqueda de contactos en función de su profesión, la ubicación geográfica o el sector industrial.

Una alternativa menos selectiva para la socialización entre profesionales es la que proporciona Ryze (http://www.ryze.com). A diferencia del anterior, la extracción ocupacional de los subscriptores es mucho más diversa, y el programa facilita tanto la organización de foros como una descripción detallada de la propia trayectoria

\footnotetext{
${ }^{21}$ Mark Granovetter es profesor en la Universidad de Stanford, y -como ya hemos señalado más arribatiene la consideración de "clásico" de la literatura de análisis de redes sociales por su trabajo sobre "la fuerza de los lazos débiles": Granovetter, M.S. (1973). The strength of weak ties. American Journal of Sociology, 78 (6), 1360-1380.
} 
profesional. Ryze organiza encuentros cara a cara en ciudades de Estados Unidos, en las que los miembros pueden remitir invitaciones. Se trata del único programa que ha superado la versión Beta, y -aunque la subscripción es gratuita- cobra por tener acceso a las búsquedas de información.

La plataforma española. Econozco (http://www.econozco.com) es la primera iniciativa de networking profesional en castellano. En este terreno llegar el primero supone un activo muy importante, pues facilita la formación de una clientela - una masa crítica- que se transforma de inmediato en una ventaja competitiva fundamental frente a potenciales competidores. No en vano, el número y las características de los miembros forman parte del servicio que se proporciona.

Econozco cuenta con un diseño muy cuidado y atractivo, que le hace destacar en comparación con las aplicaciones anglosajonas. También el formato de búsqueda resulta muy práctico. El perfil personal informa de las preferencias de contacto, junto a otros detalles sobre la trayectoria profesional. Como contenido adicional, actualiza un listado de los blogs de sus miembros en tiempo real.

Econozco ofrece networking profesional genérico, en la línea de Ryze. De partida, el programa muestra una representación gráfica de la red a dos grados de distancia del usuario: sus contactos directos, y "los amigos de sus amigos". Sin embargo, a través de contactos encadenados, las solicitudes de ayuda pueden alcanzar los seis pasos de distancia. Esto significa, de acuerdo con la lógica de mundo pequeño, que cualquier usuario podría acceder prácticamente a toda la red global. En comparación, sitios de networking profesional como Ryze aplican un criterio conservador de dos grados en las oportunidades de contacto. En Econozco existe un filtro por el que sólo personas a dos grados de distancia pueden remitir la solicitud de contacto, pero la posibilidad de componer cadenas de seis grados puede ser una distancia social demasiado grande como para que la confianza se mantenga. Aunque en la fase de consolidación de la plataforma puede ser práctico abrir el rango de oportunidades de contacto, con el tiempo esta característica puede convertirse en poco funcional.

\section{Software orientado al networking y nuevas formas de sociabilidad}

Las técnicas de networking tienen una larga tradición en el mundo de los negocios. Por eso no es de extrañar, como acabamos de comprobar, que se esté desarrollando software en ese terreno. Sin embargo, las aplicaciones que han tenido mayor proyección pública, con diferencia, han sido las comunidades electrónicas en las que los usuarios comparten información sobre su red de contactos para establecer nuevas relaciones. Parte de este éxito tiene que ver con el amplio eco de una de las iniciativas puestas en marcha en la bahía de San Francisco. Friendster (http://www.friendster.com) ha superado los 3 millones de miembros en algo más de un año de funcionamiento. Eso hace de esta comunidad todo un experimento social, al que es imprescindible referirse para valorar el 
alcance de los nuevos patrones de relación ${ }^{22}$.

Los usuarios de Friendster crean un perfil personal y hacen público qué amigos utilizan también el servicio. Tanto la subscripción como la elaboración del perfil personal son pasos muy sencillos, y permiten al usuario pasar inmediatamente a la invitación de otros amigos o a la búsqueda de relaciones. El formato para elaborar el perfil es muy flexible, y sirve para detallar aquellos intereses personales que entrarán a formar parte de los criterios utilizados por los motores de búsqueda. Las oportunidades de contacto alcanzan los cuatro grados de distancia. La clientela de Friendster está formada en su mayoría por jóvenes adultos, que utilizan el servicio con frecuencia para el establecimiento de citas.

Los competidores de Friendster apenas alcanzan los 10.000 o los 60.000 miembros, con lo que están lejos de convertirse en el fenómeno social que es actualmente el líder del sector. Por ejemplo, Friendzy (http://www.friendzy.com) ha elegido al público más joven como población diana, y de acuerdo con ello cuenta con un diseño especialmente atractivo, que permite además elaborar un perfil personal amplio.

Una iniciativa más prometedora por sus planteamientos es Tribe.net (http://www.tribe.net): en este caso se combina la plataforma para la búsqueda de relaciones con pequeños grupos de interés que generan sus propios contenidos. Una vez que se define el perfil personal, el usuario puede incorporarse a diferentes "tribus", que constituyen grupos interesados en un tema, o pequeñas comunidades virtuales. Posteriormente, la pertenencia a dichos grupos sirve para concretar el perfil personal. Así, las "tribus" funcionan como grupos de discusión, y canalizan el networking a través de la participación en comunidades. A todo ello se suma la posibilidad de anunciar en el perfil personal ofertas, servicios y oportunidades de trabajo.

\footnotetext{
${ }^{22}$ A partir de la aparición de Friendster, las aplicaciones informáticas orientadas al networking han sido objeto de cientos de reportajes periodísticos. Al mismo tiempo, el tema del "software social" en general es uno de los asuntos de más actualidad entre los desarrolladores informáticos. En consonancia con su propia naturaleza, esta evolución también ha tenido eco en los blogs de aficionados y técnicos en informática. Un buen punto de partida para hacerse una idea del fenómeno es Many To Many (http://www.corante.com/many), un blog en el que escriben algunos de los expertos en Internet y software social más reconocidos del momento.

Un amplio listado de este tipo de servicios (aunque con algunos errores de clasificación) puede visitarse en el enlace:

http://socialsoftware. weblogsinc.com/entry/2127913924623224.

La inflación de sitios de networking ha sido tal, que muchos usuarios se han quejado de la saturación de mensajes para confirmar nexos de amigos y conocidos. También se han desarrollado parodias de este tipo de servicios, como el sarcasmo con el que se anuncia un presunto lanzamiento de "PriceKut", una plataforma con la que Amazon haría rebajas a los clientes que comparten con sus amigos información sobre el proceso de venta: http://www.denounce.com/archives/000049.html
} 
La filosofía del servicio hace que Tribe.net esté recibiendo las mejores reseñas técnicas. Se trata de una aplicación que gestiona la identidad personal con un enfoque comunitario; ofrece contenidos y actividades -elaborados por los propios usuarios- que son una oportunidad para la socialización; y los anuncios clasificados personales se tornan en incentivos para la utilización (y re-visita) del sitio Web. Sin embargo, apenas tiene un 2 por ciento del pool de contactos del que ya dispone Friendster. Y esa bolsa de subscriptores resulta una cuestión clave, pues en las herramientas de networking parece que el número de miembros no es sólo parte de la oferta, sino que informa también del ritmo - y el potencial- de crecimiento de la red.

Visita la tabla comparativa de aplicaciones de networking

\section{Las redes como interface socio-tecnológica}

Desde los primeros trabajos de Stanley Milgram y Manfred Kochen la idea de las cadenas de conocidos ha seducido la imaginación literaria y científica. En este apartado hemos comprobado precisamente los progresos del software social, en su esfuerzo por capitalizar el potencial de los vínculos personales. Sin embargo, el uso instrumental de la interacción humana tiene que acomodarse -lógicamente- a la propia naturaleza de la relación social. Por eso las especificaciones del diseño están obligadas a tomar como referencia la dinámica social y psicológica que ponen en juego. Los primeros proyectos experimentales muestran que la puesta en práctica de aplicaciones de networking podría beneficiarse de hacer suyos -entre otros- los siguientes razonamientos:

- La confianza social no se mantiene de conocido en conocido con independencia de la longitud de la cadena. Es decir, no hay una propiedad transitiva universal que permita, por ejemplo, a un vendedor aprovecharse de que el cliente al que quiere colocar la mercancía es el amigo del amigo del amigo de un amigo. De hecho, el valor de un contacto puede ir atenuándose a medida que nos acercamos a un objetivo, pues parafraseando al propio Milgram- un recorrido de "sólo seis pasos" puede ser en la práctica una distancia social muy amplia.

- En segundo lugar, la acumulación de contactos carece de sentido como fin en sí mismo. El lema de algunas de las aplicaciones revisadas podría ser "cuanto mayor conectividad social mejor", en la medida en que promueven una dinámica competitiva de acaparamiento individual de relaciones. Sin 
embargo, esa aspiración de crecimiento poco realista - que no respeta el tempo y el contexto de las relaciones personales-, acaba por minar el mantenimiento de las conexiones que pretende promover.

- Finalmente, revelar el propio capital relacional es un paso que muchos usuarios llevarán a cabo con reservas. Publicar la red personal - aún siendo a un número determinado de subscriptores que, como contrapartida, han hecho previamente lo mismo- no sólo requiere de los controles técnicos adecuados para garantizar la privacidad de la información. La sinceridad y la modalidad de la respuesta también dependen en este caso de los incentivos para compartir un capital en el que se ha invertido una parte importante de la historia personal o profesional.

A pesar de todo, son muchas las evidencias anecdóticas que apuntan que este tipo de plataformas "funciona". Los reportajes periodísticos suelen apoyarse en experiencias de usuarios que han obtenido un rendimiento personal como consecuencia de su participación en alguna de ellas. En cierto modo, se trata de lugares de encuentro que constituyen campos sociales con una lógica propia (a veces con independencia del diseño tecnológico). Unos son sitios exclusivos para directivos de alto nivel, mientras que otros están abiertos a todo tipo de participantes. La vitalidad de los núcleos urbanos de Boston, Nueva York y la Bahía de San Francisco $-y$, por extensión, Estados Unidos- aporta el grueso de los usuarios de este tipo de servicios en la actualidad. Muchos son jóvenes profesionales que han cambiado su lugar de residencia por motivos laborales.

Por eso - quizá con la excepción de Visible Path y Spoke, que tratan de sacar partido a datos relacionales-, la virtualidad de estas aplicaciones consiste fundamentalmente en ofrecer un espacio en el que hacer contactos personales. Hasta cierto punto el diseño puede afectar a los patrones de relación. Por ejemplo, los sitios de networking profesional permiten normalmente las solicitudes de contacto entre participantes a dos pasos de distancia, mientras que los sitios para el establecimiento de citas abren el círculo hasta los cuatro grados. Pero también es cierto que la sociabilidad se expresa a veces por encima de eventuales impedimentos técnicos. En el caso de Friendster, donde no están previstas las agrupaciones en torno a temas de interés (como las "tribus" de Tribe.net), los usuarios crean personajes que representan organizaciones y lugares. De ese modo, dar de alta un perfil con el nombre - por ejemplo- de "Universidad de Harvard" permite crear un grupo de alumnos de dicha institución ${ }^{23}$. Es decir, la participación

${ }^{23}$ Es un caso documentado por Cade Metz (2004). La creación de personajes ficticios también ha sido 
a través de grupos y comunidades busca la forma de expresarse aunque no esté prevista por la plataforma tecnológica.

Desde nuestro punto de vista, la mayoría de los sitios de networking revisados se asimilan al correo electrónico, los foros de discusión, los grupos de noticias, las listas de distribución y otros entornos de comunicación a través de Internet, que amplían las posibilidades de contacto personal. Aunque - hasta donde alcanza nuestro conocimiento- no hay evaluaciones sistemáticas del impacto de estas aplicaciones en las redes personales, es de suponer que tienen un efecto similar al resto de entornos (que ofrecen oportunidades para el establecimiento y el mantenimiento de contactos, facilitan la incorporación de vínculos débiles, y sirven para aumentar la diversidad socio-demográfica de las redes personales ${ }^{24}$ ). Son una muestra, en ese sentido, del proceso de "individualización" (que hace referencia a la progresiva personalización de la vida comunitaria y el uso instrumental de las relaciones sociales). Friendster lo anuncia de hecho explícitamente en su página de inicio, en los siguientes términos: "crea tu propia comunidad personal y privada, donde puedes relacionarte con gente que está conectada a través de redes de amigos mutuos".

Esas experiencias con cadenas de conocidos están sirviendo para popularizar la idea de red social. Sin embargo, las aplicaciones del análisis sistemático de redes sociales apenas van más allá de la representación visual y el uso metafórico de la idea de red. Como hemos comprobado, sólo los programas específicos para los departamentos de ventas adoptan una orientación analítica ${ }^{25}$. Pero las grandes bases de datos relacionales que se están formando de modo natural a partir de la participación de los usuarios, son sin lugar a dudas una oportunidad para la investigación y el desarrollo del análisis de redes. La combinación de (a) un "experimento natural" sobre la conectividad social con (b) un ámbito aplicado en

\footnotetext{
una práctica frecuente, y ha sido objeto de control por parte de los administradores del sitio.

24 Se trata - básicamente- de bancos de datos de registros personales, en los que la lógica de funcionamiento en cadena - aún siendo metafórica- podría redundar en la endogamia de las relaciones. Cabe preguntarse, en ese sentido, cuál es el incentivo de los profesionales para revelar una información sobre su red personal que podría amenazar los "agujeros estructurales" (en la terminología de Burt) de los que obtienen rendimientos particulares.

${ }^{25}$ Visible Path utiliza indicadores de centralidad e intermediación en un contexto de relación específico: la compra-venta. Es el programa que ha recibido mejores críticas de los especialistas en análisis de redes sociales. Por lo demás, la comunidad científica ha recibido con cierto recelo los desarrollos de networking, poniendo en cuestión el uso comercial de los desarrollos científicos y la amenaza a la privacidad de la información. Por ejemplo, en la lista de correo de la International Network of Social Network Analysis <SOCNECT@lists.ufl.edu> ha habido amplias discusiones sobre las patentes de los algoritmos de análisis, y se advierte de los usos lesivos que podrían derivarse de las bases de datos con registros personales.
} 
desarrollo, pueden resultar muy productivas para la exploración científica. Teniendo en cuenta las características de los programas informáticos de networking, tres líneas de investigación parecen a priori especialmente pertinentes:

- En primer lugar, la construcción de redes globales a partir de redes personales forma parte de la dinámica de funcionamiento habitual de algunos de estos sitios Web. Por eso son de utilidad las técnicas para construir redes sociométricas a partir de datos egocéntricos. El programa SocioMetrica LinkAlyzer (http://www.mdlogix.com/id154.htm) se está diseñando precisamente con esos fines ${ }^{26}$. En el plano teórico, guarda relación con los modelos para la determinación de comunidades (entendidas como estructuras "meso", en la acepción de Alexis Ferrand). Y, en última instancia, remite a la elaboración de una teoría sobre el muestreo y la representatividad de los datos relacionales.

- El segundo componente del servicio consiste en el uso individual de la trama general de contactos. La funcionalidad de este tipo de prestaciones depende de cómo perciben y utilizan la red global los actores individuales, a partir de la información local disponible. Esa idea se corresponde, por ejemplo, con el estudio de las estrategias de búsqueda y navegación en redes complejas (en la línea de los trabajos sobre la estructura de Internet de Jon Kleinberg). Otro tema que merece atención específica es el examen de los cambios que experimentan las estrategias y patrones de vinculación personal después de obtener información sistemática sobre la estructura y la composición de la propia red $^{27}$.

- Por último, una tercera aplicación que merece la pena destacar es la monitorización del crecimiento de las redes. Hemos comprobado que la difusión a través de Internet permite la constitución de bases de datos amplísimas, de modo que el análisis de redes podría aprovecharlas como materia de estudio. Al mismo tiempo, es una herramienta para gestionar la evolución del tejido de relaciones. Concretamente, los modelos estadísticos

\footnotetext{
${ }^{26}$ El programa utiliza los atributos de los nodos para determinar si diferentes informes corresponden a un mismo individuo, estableciendo así una red global. El software está en desarrollo, y está previsto incorporar herramientas para la recogida de datos egocéntricos, así como otras aplicaciones estadísticas.

${ }^{27}$ Por ejemplo, con listas de correo electrónico se ha utilizado la técnica "Netmirror", consistente en dar feedback a los participantes sobre la estructura de sus relaciones. Generalmente, estos grupos se organizan en torno a un pequeño número de actores-clave, que ven reforzada su participación después de obtener feedback a través de un sociograma de sus intercambios de correo electrónico (Véase, Borgatti y Molina, 2002).
} 
desarrollados por Tom Snijders para datos longitudinales de redes (junto con el programa SIENA asociado), proporcionan una referencia de la que derivar aplicaciones en este campo.

A partir de estos tres ejes de desarrollo, hay razones suficientes para pensar que las aplicaciones del análisis de redes tienen mucho que aportar a los programas informáticos de networking. Pero para ello será necesario recorrer un largo camino, empezando por preparar las bases de datos de modo que puedan aplicarse las técnicas de redes. Por ejemplo, las plataformas revisadas carecen generalmente de información temporal sobre el establecimiento de los vínculos, haciendo inviable determinar cuándo se conectó (o se desconectó) un grafo. En consecuencia, salvo contadas excepciones, los primeros análisis científicos en este campo suelen empezar elaborando su propia matriz de datos, a través de un análisis cualitativo previo de los intercambios en la red.

Pero es necesario recordar que estos programas están dando sus primeros pasos. Al mismo tiempo, los congresos centrados en el software social empiezan a incorporar paulatinamente el enfoque de redes ${ }^{28}$. No sería de extrañar que la segunda generación del networking informático se caracterice por un mejor aprovechamiento del conocimiento científico sobre redes sociales.

\section{Matrix y la metáfora de la red}

Como se ha visto, un alto porcentaje de las herramientas de búsqueda no utiliza el análisis de redes sociales. Para el grueso de los buscadores más utilizados la punta de lanza es - por el contrario- el desarrollo de algoritmos de búsqueda propios, autónomos y efectivos que garanticen un nivel elevado en la relevancia de los resultados obtenidos. Sin embargo, aunque un grupo de buscadores sólo recurre a la metáfora de la red para ilustrar los resultados en una imagen, también es cierto que otros buscadores "emergentes" están empezando a aplicar algunos de sus métodos: es el caso de la "bola de nieve", por ejemplo, por parte de Amazon y de Touchgraph.

Pero no debemos pasar por alto que otro elemento -igualmente significativosubyace en la noción de los buscadores: Internet es una red, y de esta idea se sirven los algoritmos de búsqueda. En este contexto han demostrado evolucionar satisfactoriamente, como auténticas herramientas centinelas de la información. Es probable que en breve el análisis de redes sociales comience a mirar hacia los

${ }^{28}$ Véanse, como ejemplo, los congresos citados por Isidro Maya Jariego en la lista REDES de Rediris [Mensaje de 1 de febrero de 2004, ID: 003301c3e905\$40257210\$0201a8c0; disponible en: http: / / listserv. rediris. es/cgi-bin/wa? $A 2=$ ind $0402 \& L=$ redes $\& D=1 \& T=0 \& O=D \& F=\& S=\& P=68]$. 
algoritmos utilizados por los buscadores más efectivos, como un complemento plausible a los métodos más recurridos en la construcción de imágenes de redes sociales. Este puede ser el caso, por ejemplo, en la identificación de comunidades y conglomerados.

En ese sentido, una de las metas que persiguen los buscadores de información en Internet es dar apariencia de cuerpo ordenado a la ingente cantidad de información, proporcionando resultados relevantes para sus usuarios. Además, aunque el movimiento pro-software libre a escala mundial avanza a pasos de gigante, los buscadores - en tanto empresas- aspiran a ser sostenibles, y gran parte de sus avances dependen de un fuerte impulso en I+D. Los buscadores pretenden ser -al mismo tiempo- efectivos en la búsqueda de información para los usuarios, y eficientes para las empresas que los utilizan como intermediarios para llegar a su clientela. Las estrategias aplicadas para conseguir dichos objetivos diferencian a unos buscadores de otros ${ }^{29}$.

La aplicación activa de algunas técnicas de análisis de redes sociales a los algoritmos de búsqueda podría contribuir en el logro de ambos objetivos, (a) obtener resultados relevantes y (b) conectar a usuarios con empresas. Un ejemplo podría ser la incorporación de técnicas de análisis textual y lingüístico. Sin embargo, es sólo un comienzo. Otra opción consiste en el almacenamiento de información sobre las búsquedas anteriores de cada usuario a través de cookies, facilitando la realización de búsquedas recursivas. Por ejemplo, después de enviar información sobre búsquedas anteriores, el usuario puede conocer quiénes han hecho búsquedas similares, y qué otras consultas han realizado. Este tipo de prestaciones pretende mejorar la relevancia de los resultados, proporcionando simultáneamente información sobre las perspectivas de otros usuarios.

La segunda dimensión en la que hemos reparado tiene que ver con la búsqueda y establecimiento de contactos personales. La estructura de Internet, tal y como afirma Castells ${ }^{30}$, ha planteado desde el inicio de su difusión la sospecha de que se podría llegar a interactuar con personas a través de una forma alternativa de

\footnotetext{
${ }^{29}$ La de Google por ejemplo pareciera ser atender a estudios de marketing. Éstos pueden dar parte de la respuesta en tanto que los usuarios y los clientes de esas empresas están "pre-catalogados" de forma en que los gustos aparecen ordenados en función de las búsquedas realizadas: a X búsquedas, $X$ intereses que son mostrados en forma de "text ads" en el lado derecho de la ventana del navegador. La segunda opción, pareciera ser la del portal Yahoo, y consiste en partir del supuesto de que "a todos interesa cualquier cosa" y en función de éste se presenta, a lo largo de un trabajo de búsqueda una cantidad elevada de ads publicitarios que intentan seducir el destino de los clicks.
}

${ }^{30}$ Castells, M. (2003). La Galaxia Internet. España: Plaza y Janés. 
comunicación. Esto daría lugar a una estructura de relaciones paralela a la tradicional, sustentada básicamente, en el correo electrónico (ya que constituye más del 80\% del uso de Internet) (Castells, 2003:139). Lo cierto es que esta posibilidad no parece haberse materializado ni siquiera a través de los juegos de rol en línea. La interacción social en la red no parece tener un efecto directo sobre la configuración de las relaciones fuera de ésta, "más allá de añadir la interacción en línea a las relaciones sociales previamente existentes" (Castells, op.cit: 140). Sin embargo, sí hay indicios para pensar que el uso de Internet puede llegar a sustituir algunas actividades sociales, aunque más como parte de la evolución general de los modelos de interacción social y "su relación con los soportes materiales en que se desarrolla dicha interacción: espacio, organizaciones, tecnologías de la comunicación" (ibid: 146).

Quizás esperanzadas en este potencial, las aplicaciones de networking han abierto la veda para la construcción de redes personales en línea, así como la potenciación de su valor intrínseco. Aún es pronto para concluir sobre su efectividad, en especial porque su difusión parece obedecer al seguimiento de una moda. En la actualidad constituyen comunidades en línea que utilizan la idea de "cadena de conocidos" para estimular el intercambio entre participantes. Muchas veces son en la práctica nada más que bases de datos de registros personales. Pero hemos pretendido demostrar que el análisis de redes sociales puede aportar técnicas y conocimientos con los que mejorar su funcionamiento en el futuro.

Un nuevo desarrollo del que habrá que estar pendientes es la convergencia de las herramientas de networking con los buscadores de Internet. Eurekster (http://www.eurekster.com/) es un buscador en versión Beta que permite la obtención de resultados personalizados. El usuario va elaborando rankings con sus preferencias en los resultados - a medida que los obtiene y los consulta-, de modo que dicha información orienta sus búsquedas posteriores. El sistema permite, además, compartir los rankings de preferencia con amigos y conocidos, orientando las búsquedas de terceras personas por aquello que el usuario focal haya considerado útil.

Un dato más para confirmar que aún estamos asistiendo a los primeros momentos de la conformación del nuevo entramado socio-técnico. A lo largo de estas páginas hemos querido ver en Internet un dispositivo de entrada y salida a Matrix, esa realidad difusa, confusa y extraña, construida como una maraña de telarañas de información. 


\section{Bibliografía}

Agre, P. (2001). "Networking on the network". Publicación personal disponible en: http://dlis.gseis.ucla.edu/pagre/

Arasu, Arvind et al (2001). "Searching the web". En ACM Transactions on Internet Technology.

Barabási, A. L. (2002). Linked. The new science of networks. Perseus Publishing: Cambridge, Massachusetts.

Borgatti, S.P., Everett, M.G. and Freeman, L.C. 2002. Ucinet for Windows: Software for Social Network Analysis. Harvard: Analytic Technologies.

Borgatti, S. \& Molina, J. L. (2002). "What can social network analysis do for management consulting". Building Effective Networks Conference, Academy of Management, Denver, Colorado, 9 a 14 de agosto.

Boyd, S. (2003). "Cracking the social code. Can networking tools work their magic on your bottom line?", Darwin Magazine, Information Technology for Executives, September.

Castells, M. (2003). Galaxia Internet. España: Plaza y Janés.

CNN.com (2004). "Better search results than Google". 5 de enero.

Cowley, S. (2004). "Google gets social. Search giant tests a new social networking site", PC World, January.

Davies, W. (2003). You Don't Know Me, but... Social Capital \& Social Software. London: iSociety \& The Work Foundation.

Fadner, R. (2004). "How to use friends to influence people's search: next generation engine exploits social networking", MediaPost Communications, January. Ferrand, A. (2002). "Las comunidades locales como estructuras 'meso'", Revista Redes. (3), \#4.

Gunn, E. (2004). "Expand your connections through online networking", The Wall Street Journal: Career Journal, $21^{\text {th }}$ January.

Hargittai, E. (2004). "Do you google? Understanding search engine use beyond the hype", First Monday, 9 (3), March. Disponible en: http://www. firstmonday.org/issues/issue9 3/hargittai/

Hindmand, Mathew et al (2003) "'Googlearchy' How a few heavly-linked sites dominates politics on the web" Documento presentado en la Annual Meeting of the Midwest Political Science Association.

Holme, P., Edling, C. R. \& Liljeros, F. (2004). "Structure and time evolution of an Internet dating community", Social Networks, 26, 155-174.

J ordan, K., Hauser, J. \& Foster, S. (2003). "The augmented social network: building identity and trust into the next-generation Internet", A report for the Link Tank. 
Kahney, L. (2004). "Social nets not making friends", Wired, $28^{\text {th }}$ January.

Kahney, L. (2003). "Looking toward a networked world", Wired, $29^{\text {th }}$ October.

Kleinberg, J. (2000). "Navigation in a Small World", Nature 406, 845.

Kramer, D. (2003). Social Networking as applied to Knowledge Transfer \& Exchange. Report to Jane Brenneman Gibson.

Litow, Bruce (2001) “A review of World Wide Web searching techniques, focusing on HTTS and related algorithms that utilise the link topology of World Wide Web to provide the basis for a structure based search technology" Sin más información.

Maya Jariego, Isidro (2003). Internet, amigos y bacterias: la alargada sombra de Stanley Milgram. Araucaria. Revista Iberoamericana de Filosofía, Política y Humanidades, 5 (10), 3-14. Disponible en:

http://www.us.es/araucaria/ideas10_1.htm.

Metz, C. (2004). "Make contact", PC Magazine, January.

Modha, D. (2000). "Clustering hypertext with applications to web searching", documento presentado en la ACM Hypertext Conference.

Pescovitz, D. (2003). "The Best New Technologies of 2003", Business 2.0, November.

Rakhsham, Arash, Lawrence Holder y Diane J. Cook (2003) "Structural web search engine" en American Association of Artificial Intelligence (http://www.aaai.org).

Snijders, T. A. B. (2001). "The Statistical Evaluation of Social Network Dynamics". En M. E. Sobel \& M. P. Becker (Eds.), Sociological Methodology, 361-395. Boston and London: Basil Blackwell.

Terdiman, D. (2003). "Friendster quickly gathering foes", Wired, $21^{\text {th }}$ november.

Tien, A. Y. (2003). "The SocioMetrica SBIR Project", XXIII International Sunbelt Social Network Conference. Cancún (México), 14-17 de febrero de 2003.

Wilf, S. Herbert (2001) "Searching the web with eigenvectors". University of Pensylvania, Philadelphia. 
Tabla comparativa de las características de los buscadores más destacados

\begin{tabular}{|c|c|c|c|c|}
\hline Software & Descripción & Destaca por & Puntos fuertes & Puntos débiles \\
\hline Google & $\begin{array}{l}\text { Buscador con algoritmo de } \\
\text { búsqueda propio. }\end{array}$ & $\begin{array}{l}\text { La rapidez y efectividad de sus } \\
\text { búsquedas. Innovación en los } \\
\text { anuncios publicitarios. }\end{array}$ & $\begin{array}{l}\text { Innovación, servicios alternativos no sólo para } \\
\text { las búsquedas avanzadas, sino también para } \\
\text { búsquedas temáticas }\end{array}$ & $\begin{array}{l}\text { La actualización de los índices de las páginas } \\
\text { “Google dance”, afectan de manera importante } \\
\text { los resultados obtenidos mientras se realiza. Hay } \\
\text { importantes modificaciones "artificiales” en el } \\
\text { puesto que ocupan las páginas en virtud de } \\
\text { manipulación del page rank, producto de una } \\
\text { inflación artificial de su tráfico. }\end{array}$ \\
\hline Yahoo & $\begin{array}{l}\text { Buscador innovador en sus } \\
\text { comienzos y que hasta hace } \\
\text { poco trabajó en colaboración con } \\
\text { Google. }\end{array}$ & La difusión de su uso. & $\begin{array}{l}\text { La gama de servicios que presta. No } \\
\text { directamente relacionados con las búsquedas, } \\
\text { aunque sí con un concepto de servicio integral } \\
\text { al usuario (e-mail, grupos, álbum } \\
\text { fotográfico...) }\end{array}$ & $\begin{array}{l}\text { Su buscador se quedó obsoleto con rapidez, y la } \\
\text { clasificación que ofrecía de los enlaces con los } \\
\text { que contaba en sus comienzos, dejó de estar } \\
\text { actualizada. }\end{array}$ \\
\hline Altavista & $\begin{array}{l}\text { Buscador en sus comienzos muy } \\
\text { asertivo y altamente visitado. }\end{array}$ & $\begin{array}{l}\text { Se destacó por la rapidez del } \\
\text { despliegue de información y su } \\
\text { exactitud. }\end{array}$ & $\begin{array}{l}\text { Introdujo la posibilidad de traducir online } \\
\text { cualquier página que se consultara. }\end{array}$ & $\begin{array}{l}\text { Al igual que Yahoo y Excite, Altavista cedió con } \\
\text { mucha rapidez terreno en favor de Google. }\end{array}$ \\
\hline Kartoo & $\begin{array}{l}\text { Uno de los primeros } \\
\text { metabuscadores con interface } \\
\text { gráfica. }\end{array}$ & $\begin{array}{l}\text { Se ha destacado por la exactitud de } \\
\text { sus resultados, además porque } \\
\text { incorpora la metáfora de red al } \\
\text { mostrar visualmente los vínculos } \\
\text { entre las páginas en virtud de sus } \\
\text { enlaces. }\end{array}$ & $\begin{array}{l}\text { Su representación gráfica. Es el precursor de } \\
\text { los metabuscadores gráficos y la imagen } \\
\text { resultante no sólo muestra los vínculos sino } \\
\text { también la relevancia de cada sitio, ilustrada } \\
\text { por el diferente tamaño de los nodos. } \\
\text { Actualmente Kartoo comercializa } \\
\text { herramientas de intranet para empresas, pero } \\
\text { conserva la gratuidad de su metabuscador. }\end{array}$ & $\begin{array}{l}\text { El tiempo de carga. Es un metabuscador no apto } \\
\text { para conexiones lentas ni para entornos con } \\
\text { pocas capacidades gráficas. La posibilidad de } \\
\text { utilizar una barra de Kartoo similar a la } \\
\text { desarrollada por Google (Google Toolbar) o Yahoo } \\
\text { (Yahoo Companion) es muy inestable, e incluso } \\
\text { perjudica el desempeño del navegador Internet } \\
\text { Explorer. Al igual que sus rivales, esta barra de } \\
\text { búsqueda no puede ser utilizada en otro } \\
\text { navegador distinto al Explorer. }\end{array}$ \\
\hline Touchgraph & \begin{tabular}{|l|} 
Más que un buscador, es un \\
"ilustrador de relaciones". Se \\
perfila como un "network \\
explorer" que permite observar \\
cómo se conforma la red de una \\
dirección determinada en función \\
de los enlaces a los que apunta y \\
los enlaces que apuntan a él. \\
\end{tabular} & $\begin{array}{l}\text { La posibilidad de modificar la } \\
\text { disposición del gráfico de la red con } \\
\text { un simple movimiento de "arrastre" } \\
\text { del cursor. }\end{array}$ & $\begin{array}{l}\text { Su interface gráfica es bastante cercana a la } \\
\text { idea de los grafos. Y es muy intuitiva, } \\
\text { permitiendo que el usuario controle las } \\
\text { etiquetas que se muestran en el gráfico } \\
\text { resultante, así como los colores, tamaño y } \\
\text { profundidad de detalle del gráfico. }\end{array}$ & $\begin{array}{l}\text { Funciona bajo entorno Java. Buena parte de los } \\
\text { Sistemas Operativos actualmente en uso incluyen } \\
\text { este entorno ideal para aplicaciones dinámicas y } \\
\text { que es independiente de la plataforma en que se } \\
\text { ejecute. Sin embargo, la lentitud de carga es un } \\
\text { problema importante. }\end{array}$ \\
\hline Grokker & $\begin{array}{l}\text { Es la última generación de } \\
\text { metabuscadores gráficos. }\end{array}$ & $\begin{array}{l}\text { La búsqueda puede realizarse con } \\
\text { independencia del navegador con el } \\
\text { que se trabaje, ya que trabaja con } \\
\text { una aplicación que se instala en el } \\
\text { ordenador de forma residente. La } \\
\text { interface gráfica es interesante y } \\
\text { ofrece al usuario una clasificación } \\
\text { temática, punto de partida inicial } \\
\text { para quien obtiene información } \\
\text { sobre un tópico que le es } \\
\text { desconocido. Esta clasificación es } \\
\text { mostrada a través de círculos o } \\
\text { cuadrados concéntricos que } \\
\text { permiten agrupar información } \\
\text { obtenida de sitios similares. } \\
\end{array}$ & $\begin{array}{l}\text { Su interface gráfica es bastante intuitiva. El } \\
\text { usuario puede controlar la apariencia de los } \\
\text { resultados obtenidos: profundidad de la } \\
\text { búsqueda, los buscadores utilizados, la forma } \\
\text { en que se mostrarán los resultados } \\
\text { (cuadrados o círculos), y además puede } \\
\text { penetrar en cada uno de los círculos } \\
\text { resultantes y escudriñar en los resultados } \\
\text { obtenidos, al tiempo que modificarlos } \\
\text { eliminando nodos en función de su pertinencia. }\end{array}$ & $\begin{array}{l}\text { El número de nodos repetidos y el índice de } \\
\text { redundancia de la información son elevados. Los } \\
\text { filtros parecieran insuficientes para evitar que el } \\
\text { trabajo de depurar la información no pertinente } \\
\text { recaiga en el usuario final. No se trata de un } \\
\text { buscador de gratuito. }\end{array}$ \\
\hline
\end{tabular}




\begin{tabular}{|c|c|c|c|c|}
\hline Software & Descripción & Destaca por & Puntos fuertes & Puntos débiles \\
\hline Visible Path & $\begin{array}{l}\text { Plataforma de almacenamiento y } \\
\text { análisis de datos relaciones en los } \\
\text { departamentos comerciales, para } \\
\text { reducir el ciclo de comercialización. }\end{array}$ & $\begin{array}{l}\text { Aplicación de algoritmos de análisis de } \\
\text { redes sociales, que permiten elaborar un } \\
\text { mapa de relaciones, examinar los patrones } \\
\text { de conectividad y trazar los caminos más } \\
\text { cortos hacia un cliente potencial. }\end{array}$ & $\begin{array}{l}\text { Cuenta con resultados económicos contrastados. La } \\
\text { integración en un contexto específico permite un } \\
\text { diseño especializado de sus funciones. Los requisitos } \\
\text { de control y privacidad están por encima de los } \\
\text { estándares del sector. Los intermediarios son } \\
\text { identificados (y pueden ser compensados por el } \\
\text { contacto que proporcionan). }\end{array}$ & $\begin{array}{l}\text { Su potencial se irá perfilando con la } \\
\text { práctica, a medida que se desarrollen } \\
\text { nuevos algoritmos específicos para la } \\
\text { situación de intermediación en } \\
\text { compraventa. }\end{array}$ \\
\hline Spoke & $\begin{array}{l}\text { Aplicación cliente que se integra } \\
\text { con el sistema de correo } \\
\text { electrónico para elaborar una } \\
\text { representación de la red personal. }\end{array}$ & $\begin{array}{l}\text { El software también hace búsquedas en la } \\
\text { Web para compilar perfiles de clientes } \\
\text { potenciales, señalando sus peculiaridades e } \\
\text { intereses. }\end{array}$ & $\begin{array}{l}\text { Facilidad de uso. El usuario decide qué información } \\
\text { de sus contactos y su libreta de direcciones sea } \\
\text { analizada. Compartir información sobre los contactos } \\
\text { es una funcionalidad específica que el usuario tiene } \\
\text { que aprobar. Se obtiene una representación de la red } \\
\text { personal. }\end{array}$ & $\begin{array}{l}\text { Su competidor más directo, Visible Path, } \\
\text { cuenta con un posicionamiento más } \\
\text { definido y obtiene mejores referencias en } \\
\text { las reseñas técnicas. }\end{array}$ \\
\hline Linkedin & $\begin{array}{l}\text { Club de contactos profesionales de } \\
\text { alto nivel. }\end{array}$ & $\begin{array}{l}\text { La composición de su clientela constituye } \\
\text { una elite de los negocios, convirtiéndola en } \\
\text { un recurso excelente para el reclutamiento } \\
\text { de personal, la búsqueda de inversión y la } \\
\text { obtención de consultoría. }\end{array}$ & $\begin{array}{l}\text { Cuenta con un mecanismo selectivo en las solicitudes } \\
\text { de ayuda, evitando la saturación de los participantes. } \\
\text { Facilidad de uso. Control adecuado de la privacidad } \\
\text { de los participantes. }\end{array}$ & $\begin{array}{l}\text { Es necesario cultivar los contactos, pues } \\
\text { de otro modo el ámbito de oportunidades } \\
\text { es muy limitado y la red poco activa. }\end{array}$ \\
\hline Ryze & $\begin{array}{l}\text { Servicio de contacto entre } \\
\text { profesionales. }\end{array}$ & $\begin{array}{l}\text { Es la única que no se encuentra en versión } \\
\text { Beta, y que cobra los servicios de búsqueda } \\
\text { de información. }\end{array}$ & $\begin{array}{l}\text { La plataforma ha superado la fase experimental. } \\
\text { Facilidad de uso. Se pueden mandar invitaciones } \\
\text { para encuentros cara a cara, cuando se organizan en } \\
\text { la ciudad "Ryze meetings". }\end{array}$ & $\begin{array}{l}\text { Es necesario pagar una subscripción para } \\
\text { hacer uso del servicio, limitando el } \\
\text { potencial de crecimiento de la red. El } \\
\text { diseño es poco atractivo. }\end{array}$ \\
\hline Econozco & $\begin{array}{l}\text { Primera plataforma de networking } \\
\text { profesional en castellano. }\end{array}$ & $\begin{array}{l}\text { Está en versión Beta, pero pretende ser en } \\
\text { adelante en todos sus servicios totalmente } \\
\text { gratuita. Primer servicio en español. }\end{array}$ & $\begin{array}{l}\text { Facilita el uso y potencia los contactos entre los } \\
\text { miembros de una red, hasta una distancia de seis } \\
\text { grados y a través de esta ruta. Importante nivel de } \\
\text { privacidad para sus miembros. Muestra una } \\
\text { representación gráfica de la red en una ventana o a } \\
\text { pantalla completa. Muestra un listado de estadísticas } \\
\text { de la red en términos de área geográfica de sus } \\
\text { miembros, temas de preferencia y preferencia de } \\
\text { contacto. Actualiza un listado de blogs de sus } \\
\text { miembros en tiempo real. }\end{array}$ & $\begin{array}{l}\text { Sólo lleva unos meses en } \\
\text { funcionamiento, por lo que habrá que } \\
\text { esperar a su consolidación definitiva. La } \\
\text { oportunidad de contactar hasta seis } \\
\text { grados de distancia puede acabar } \\
\text { resultando poco funcional, especialmente } \\
\text { en un sitio de networking profesional } \\
\text { donde se aplican generalmente criterios } \\
\text { más restrictivos. }\end{array}$ \\
\hline Friendster & $\begin{array}{l}\text { Comunidad en línea que conecta a } \\
\text { la gente a través de redes de } \\
\text { amigos, para quedar o hacer } \\
\text { nuevas relaciones. }\end{array}$ & $\begin{array}{l}\text { Cuenta con más de } 3 \text { millones de } \\
\text { miembros, con algo más de un año de } \\
\text { funcionamiento. En este tipo de servicios } \\
\text { contar con "masa crítica" forma parte de su } \\
\text { funcionalidad. }\end{array}$ & $\begin{array}{l}\text { Formato de perfil personal flexible. Pone el acento en } \\
\text { la diversión y la facilidad de uso. Es un medio para el } \\
\text { establecimiento de contactos cara a cara. Facilita la } \\
\text { modificación de la red personal resultante. }\end{array}$ & $\begin{array}{l}\text { Algunos usuarios se han quejado del } \\
\text { control que hacen los administradores de } \\
\text { prácticas novedosas por parte de los } \\
\text { miembros, como inventar personajes. }\end{array}$ \\
\hline Tribe.net & $\begin{array}{l}\text { Comunidad de contactos, que } \\
\text { cuenta al mismo tiempo con } \\
\text { contenidos generados por } \\
\text { pequeños grupos de interés y } \\
\text { comunidades virtuales. }\end{array}$ & $\begin{array}{l}\text { Los usuarios pueden crear grupos de } \\
\text { interés sobre todo tipo de temas, que } \\
\text { posteriormente sirven para definir su perfil } \\
\text { personal. }\end{array}$ & $\begin{array}{l}\text { Control adecuado de la privacidad de los } \\
\text { participantes. }\end{array}$ & $\begin{array}{l}\text { La organización de la Web hace difícil } \\
\text { encontrar algunos contenidos. Para } \\
\text { aprovechar su potencial necesita } \\
\text { aumentar el número de participantes. }\end{array}$ \\
\hline Friendzy & $\begin{array}{l}\text { Comunidad de contactos orientada } \\
\text { al público más joven, entre } 18 \text { y } \\
35 \text { años. }\end{array}$ & $\begin{array}{l}\text { El perfil personal del usuario permite todo } \\
\text { tipo de detalles, destacando en } \\
\text { comparación con el resto de plataformas. }\end{array}$ & $\begin{array}{l}\text { Diseño visual atractivo. Permite incorporar mucha } \\
\text { información sobre intereses personales. }\end{array}$ & $\begin{array}{l}\text { Todavía no ha resuelto adecuadamente } \\
\text { algunos problemas con el control de la } \\
\text { privacidad. Representación de la red } \\
\text { deficiente: al ver los contactos que están } \\
\text { a cuatro grados, no muestra los nodos } \\
\text { que están a tres y dos grados como } \\
\text { intermediarios. }\end{array}$ \\
\hline
\end{tabular}

